\title{
Muziek luisteren met een kunst-oor Van probleem via uitdaging naar oplossing: handboek Musi-CI training
}

\author{
Joke Veltman
}

Stichting Musi-CI, Breda

\section{Samenvatting}

Deze bijdrage bevat persoonlijke ervaringen met luisteren met een cochleair implantaat (CI) van Joke Veltman, pianiste, Master of Music en initiatiefnemer-projectleider van de "Musi-CI training".

Deze training wordt nu ontwikkeld in samenwerking met Radboudumc en UMC Utrecht, met behulp van subsidie van ZonMw, project 'Voor Elkaar!'. Dit project loopt door tot voorjaar 2021, met als uitkomst de publicatie van het Handboek Musi-CI training, waarmee revalidatie van CI-gebruikers kan worden verrijkt.

De Musi-CI training komt tegemoet aan de wensen van CI-gebruikers én past binnen wat CI-teams kunnen bieden. De achtergronden van deze nieuwe aanpak met muziek als uitgangspunt worden besproken. Daarnaast worden ervaringen gedeeld van deelnemers aan de eerste ronde (najaar 2019) en tweede ronde (voorjaar 2020) van de Musi-CI training.

OPCI (Onafhankelijk Platform Cochleaire Implantatie) stelt dat veel CI-gebruikers blijk geven van een (grote) behoefte om weer van muziek te leren genieten (https://www.opciweb.nl).

Er zijn in Nederland ruim 7500 mensen (volwassenen en kinderen) met een CI. Jaarlijks komen hier ruim 450 mensen bij (https://www.opciweb.nl/aantal-implantaties-innederland-t-m-2019/).

\section{Introductie Joke Veltman}

Ik ben verliefd op muziek zolang ik me kan herinneren. Van kinds af aan ben ik veel met muziek bezig geweest. Naast de nette pianoles klungelde ik graag met gitaar en zingen, blokfluit spelen etc. Gelukkig ben ik zeer goed-horend begonnen en kon ik mijn pianostudie

Correspondentieadres:

J. Veltman, MMUS

Stichting Musi-CI

Fr. Rooseveltlaan 100

4835 AC Breda

E-mail: info@jokeveltmanmuziek.nl
Dit artikel is gelicentieerd onder de Creative Commons CC BY-NC-ND 4.0 (NaamsvermeldingNietCommercieel-GeenAfgeleideWerken) Internationale Licentie. Gebruik en distributie voor commerci'ele doeleinden en elke distributie van aangepast materiaal vereist schriftelijke toestemming. 
aan het Conservatorium van Amsterdam in 1980 met succes afronden. Sindsdien ben ik op veel verschillende manieren met muziek aan het werk geweest, zoals optreden (o.a. in het Schiedams Pianoduo), recensies schrijven voor de krant (o.a. voor BN/deStem), cursussen geven (o.a. voor de HOVO en de Volksuniversiteit), voorbesprekingen in het theater (o.a. in het Chassé Theater Breda) en dirigeren van amateurkoren. Sinds 1980 geef ik pianoles in mijn eigen lespraktijk.

"Dankzij" een familiaire genetische afwijking (DFNA 21) weet ik vanaf mijn 30ste jaar dat ook míjn gehoor was aangedaan. Je gehoor verliezen is voor iedereen een ingrijpend proces, maar voor een musicus misschien nog iets meer. Het raakt niet alleen je persoonlijke leven, maar raakt ook de kern van je professionele leven diep. Omdat mijn gehoorverlies geleidelijk progressief verliep kon ik me lange tijd aanpassen door mijn werk steeds zo te kiezen dat het (nog net) mogelijk was. Totdat ik eind 2012 mijn gehoor bijna geheel verloor en in juli 2013 een cochleair implantaat kreeg, een kunst-oor.

\section{Een kunst-oor...?}

Met een cochleair implantaat (CI) - een kunst-oor dat wordt geïmplanteerd in het binnenoor - kunnen dove mensen weer leren horen. Verstaan van spraak komt heel vaak weer binnen bereik, maar van muziek genieten blijkt een grote uitdaging te zijn. De spraakprocessor filtert het geluid zodat verstaan van spraak wordt geoptimaliseerd. Frequenties die voor het waarderen van muziek belangrijk zijn, worden beperkt doorgegeven, net als de fijnere informatie die zorgt voor het herkennen van timbres, zowel in spraak als bij muziek. Dit zorgt ervoor dat muziek-plezier voor veel CI-gebruikers een uitdaging blijft, ook als iemand al langere tijd luistert met een CI. Dit geldt daarnaast ook voor verstaan in lastige situaties, zoals met achtergrondgeluid of meer dan één spreker.

\section{Hoe klinkt dat kunst-oor?}

Het geluid van het CI klinkt in het begin 'zo vreemd als je nog nooit gehoord hebt', als 'rammelende vuilnisbakken, blikkerig, snerpend en met een lastige nagalm'. Na verloop van tijd treedt er meestal gewenning op aan het nieuwe geluid van het CI, waardoor de vervreemdende ervaring geleidelijk afvlakt.

Sinds ik luister met een CI (zomer 2013) krijg ik vaak de vraag 'wat hoor jij nu?' Daar is moeilijk antwoord op te geven. Ik zou net zo goed kunnen zeggen 'groener dan vroeger'... ;) Veel CI-gebruikers vertellen dat ze 'geluiden van dingen' het eerst weer als begrijpelijk herkennen, zoals vogels in de tuin, water uit de kraan en het spetteren van een eitje in de pan. Stemmen klinken vaak erg vreemd, meestal aangeduid als 'onder water geluid' of 'de stem van Mickey Mouse'. Met behulp van intensieve revalidatie wordt in het eerste half jaar 
na implantatie gewerkt aan het verstaan van complexe(re) tekst. De individuele verschillen zijn erg groot tussen wát CI-gebruikers uiteindelijk kunnen verstaan en in welke omstandigheden. Naar deze verschillen en hun oorzaken wordt op dit moment onderzoek gedaan, o.a. in Radboudumc. Er lijkt een relatie te bestaan met een muzikale voorgeschiedenis (Fuller, 2016), maar ook met de periode van gehoorverlies en doofheid (Boyen etal 2013) en het vermogen zich aan te passen aan nieuwe situaties.

\section{Muziek met een kunst-oor?}

Mijn eerste kennismaking na CI-implantatie - na ongeveer een week - met het geluid van de piano was heftig: het maakte niet uit of ik een akkoord aansloeg of met beide armen zoveel mogelijk toetsten tegelijk indrukte. Het verschil daartussen kon ik niet horen. Bij het oefenen van toonladders klonk er voor mij geen harmonische logica meer tussen de eerste toon van een toonladder en de andere tonen. Zo werd pianospelen een vervreemdende ervaring. Toen ik toevallig eens wat langer mijn toonladders herhaalde, bleek dat mijn brein na een aantal minuten toch een soort herkenning kon genereren. Dit ging niet geleidelijk, maar drong plotseling tot me door, alsof iemand ineens het licht aandeed. Dat eerste moment was schrikken. Die herkenning moest ik iedere dag terug-oefenen zodat ik de logica weer hoorde - maar geleidelijk viel het kwartje.

Uitgedaagd door de KNO-arts - “u gaat nooit meer een nieuw stuk spelen" - begon een intensieve periode van piano spelen. Hoe kon ik, inmiddels drie maanden na CI-implantatie, de weg naar muziek terugvinden? Dit ging niet alleen over muziek die ik al kende en dus in mijn auditieve geheugen zou kunnen terugvinden, maar vooral over nieuwe muziek die ik grondig wilde leren kennen.

Door toonladders en akkoorden te spelen die passen bij het muziekstuk 'under construction' werd mijn gehoor voor harmonie versterkt. In de eerste maanden moest ik dit voor ieder muziekstuk opnieuw doen, maar geleidelijk had ik dit minder nodig om harmonische logica te kunnen herkennen. Bij toeval ontdekte ik dat het behulpzaam bleek bij het ontrafelen van muziek om de handen over de toetsen verder uit elkaar te plaatsen. Hierbij verplaats je dus de linkerhand één of meer octaven naar beneden en de rechterhand één of meer octaven omhoog. Dit houdt verband met de werking van het CI. In de chip van het CI wordt berekend hoe geluid kan worden weergegeven middels elektrische pulsen via de electroden in de cochlea. Als de frequenties van geluid dicht bij elkaar liggen, moet een deel worden weggelaten omdat de electroden-bundel van het CI ze niet allemaal afzonderlijk kan coderen. Ook deelnemers aan de Musi-CI training, die het aandurven het pianospelen weer op te pakken, melden van dit verplaatsen van de handen een positief effect. Het is mooi om te merken dat zoiets kleins als een octaaf verplaatsen al zoveel effect kan hebben op de waarneming van muziek die je zelf speelt. Tenslotte bleek het voor mij goed te werken om melodische lijnen en harmonische wendingen zo vaak mee te zingen, dat ik ze uiteindelijk kon begrijpen en onthouden. Eenmaal goed gehoord bleken ze te beklijven. 
Na deze periode van weer enkele maanden heb ik uit mijn wensenlijst een pianotrio van Beethoven (opus 1, nr. 3) gekozen. Na een jaar van intensief piano spelen en muziek luisteren voelde het comfortabel genoeg om dit muziekstuk met twee professionele collega's uit te voeren.

\section{Film 'Luisteren met een kunst-oor'}

Als antwoord op de vraag 'wat hoor jij nou' maakte ik met filmmaker Jasper van Gheluwe de film 'Luisteren met een kunst-oor' (met dank aan subsidie van een fonds van UMC Utrecht). Het doel van deze film is sensibiliseren van de omgeving, zowel privé als professioneel. Meer begrip en meegevoel met wat mensen meemaken kan voor CI-gebruikers en slechthorenden een wereld van verschil maken.

De film geeft een indruk van het geluid dat het CI maakt van muziek. In het begin van de film hoor je hoe geluiden langzaam dof worden en veel van hun betekenis verliezen. Na implantatie komen de eerste begrijpelijke geluiden in beeld: alledaagse geluiden, zoals water dat uit de kraan loopt. Als je lang erg weinig hoort, vergeet je van veel dingen dat ze geluid maken. In de beginperiode met het CI is het een spannende, maar ook inspannende ontdekkingstocht om al dit geluid weer te leren kennen.

De film sluit af met bovengenoemd pianotrio van Beethoven, bewerkt naar CI-geluid. Deze bewerking stoelt op theorieën hoe het CI geluid genereert in het brein. Dit geluid kan je niet horen, alleen berekenen, omdat het CI zelf geen geluid maakt. Het CI is dus anders dan een hoortoestel, want dat is een gespecialiseerde versterker, waardoor iedereen die een hoortoestel in zijn oor stopt kan horen hoe het klinkt als geluiden versterkt worden door een kleine luidspreker in je oor. Hoe het CI precies klinkt bij elke individuele CI-gebruiker is niet bekend. Dit komt door alle persoonlijke factoren die hierbij een rol spelen én omdat wij taal missen om over geluid te kunnen communiceren.

\section{Aanpassing aan het geluid van het CI}

De mate waarin CI-gebruikers in staat zijn om het nieuwe en vaak lastige geluid van het CI te accepteren hangt van veel factoren af. Mensen die plotseling hun gehoor verliezen door ziekte of een ongeluk hebben een grote schok te verwerken. In vergelijking met een geleidelijk, progressief verlopend gehoorverlies, kan het voordeel van plotseling verlies zijn dat de auditieve verwerking en de conditie van de gehoorzenuw niet hebben geleden onder een (lange) periode van slechthorendheid. Gehoorverlies leidt tot onbalans in het verwerken van bepaalde frequenties door de cochlea, wat gevolgen heeft voor de verwerking van geluid door hersenstam, thalamus en auditieve cortex. Blijvende verandering in de organisatie van de auditieve centra in het brein kan al kort na een 'hoor-trauma' worden vastgesteld (Egger- 
mont, 2016).

Daarnaast is het natuurlijk zo dat de persoonlijke geschiedenis van CI-gebruikers ook een rol speelt. Als iemand al zijn hele leven slecht gehoord heeft en zich nooit echt met muziek heeft bezig gehouden, dan is het verlies van muziek-plezier minder aan de orde. Daartegenover staat dat mensen met een rijk gevuld auditief geheugen daar weer makkelijker op kunnen teruggrijpen. Dit laatste vraagt wel veel oefening en een flexibele houding van de CI-gebruiker. Omdat naast de condities waaronder het gehoorverlies tot stand kwam, karaktereigenschappen zo'n grote rol spelen, kan het zijn dat iemand met een rijk muzikaal verleden en een redelijk functionerend rest-gehoor toch veel last heeft van muziek-verlies en het verdriet dat daarbij komt, terwijl iemand anders in vergelijkbare omstandigheden nog (redelijk) veel met muziek doet. Zo brengt iedere CI-gebruiker zijn eigen verhaal mee, wat de groep bijzonder divers maakt.

Samenvattend kunnen we zeggen dat omstandigheden én karaktereigenschappen van elke CI-gebruiker een grote rol spelen in het proces van acceptatie en weer leren horen met het CI.

\section{Waarom is muziek zo moeilijk?}

Muziek is zo moeilijk omdat het een complex geluid is met veel details - toonhoogte, ritme, timbre, samenklanken - die allemaal bijdragen aan de betekenis van wat je hoort. De spraakprocessor van het $\mathrm{CI}$ heeft beperkte mogelijkheden deze informatie door te geven aan de gehoorzenuw en zo aan het brein. Het CI is daarbij onregelmatig verdeeld vals, wat wil zeggen dat de afstanden tussen de tonen niet meer overeenkomen met wat je gewend was te horen met een gezond gehoor. Dit maakt het volgen van melodie erg lastig en herkennen van muziek bijna onmogelijk. Dit heeft te maken met de precieze plaats waar het implantaat een bepaalde toon in de cochlea plaatst. Het binnenste vlies van de cochlea is tonotopisch gevoelig, wat wil zeggen dat iedere toon zijn eigen plaats heeft. Via het CI kan de representatie van een bepaalde toon niet precies genoeg op de juiste plaats worden geprikkeld, wat zorgt voor een onzuivere verhouding van tonen.

Sommige deelnemers aan de Musi-CI training melden dat ze het geluid van muziek zo lelijk en storend vinden, dat ze thuis - als er muziek aanstaat - roepen "die muziek uit of ik eruit". Dat is een heftige reactie. Ze mijden plaatsen met muziek, zoals festivals, concerten binnen of buiten en hebben last van achtergrondgeluid bij bijvoorbeeld TV-programma's. Zoals een deelnemer aan de Musi-CI training opmerkte: "Als je niet meer begrijpt waar je naar luistert, dan hou je ermee op".

Muziek is belangrijk in sociale situaties, waarin iedereen muziek gewoon lijkt te kunnen horen. Je deelt (vroege) herinneringen of emoties met anderen als je samen naar muziek luistert, in blije of droeve omstandigheden. Als je hierin niet kan meekomen geeft dat een 
ervaring van eenzaamheid en sociaal isolement. Zo raakt naar muziek luisteren beladen met negatieve emoties omdat het effectief vermijden van muziek nauwelijks mogelijk is. Muziek is belangrijk voor bijna alle mensen en draagt bij aan het ervaren van een gevoel van kwaliteit van leven.

Tenslotte kunnen goed-horende mensen zich vaak slecht voorstellen hoe gehoorverlies klinkt, waardoor veel slechthorenden weinig compassie in hun omgeving ervaren. Ze ervaren vaker de boodschap dat ze teveel zeuren.

\section{Hoe kan je luisteren naar muziek met een CI verbeteren?}

Om meer inzicht te krijgen in de mogelijkheden van muziek met CI deed ik een research master aan ArtEZ Conservatorium (2015-17, titel research report: 'Muziek met Cochleair Implantaat. Van herrie naar muziek'). Uit literatuuronderzoek bleek dat veel onderzoek naar muziek met CI zich vooral richt op het waarnemen van audiologische componenten, zoals kleine toonhoogteverschillen, of het kunnen herkennen van melodie of zuiver kunnen zingen. Hiermee hebben CI-dragers over het algemeen grote moeite.

Omdat de koppeling naar gerichte gehoortraining vaak ontbreekt ben ik op zoek gegaan naar een werkbare benadering van muziek voor CI-gebruikers. Als uitkomst hiervan bleek dat muziek het best opgesplitst in basiselementen (maat, ritme, toonhoogte en timbre) kan worden aangeboden, waardoor de mogelijkheid ontstaat muziek gestructureerd te benaderen. De aanpak van de Musi-CI training is een direct gevolg van deze bevindingen.

De verwachting is dat door enerzijds het uithoudingsvermogen om naar muziek te luisteren te trainen en anderzijds met veel aandacht naar geïsoleerde details, zoals timbre van instrumenten, te luisteren, CI-gebruikers de weg naar muziek weer leren te vinden.

\section{De Musi-CI training - een muzikale gehoortraining voor CI- gebruikers}

Deelnemers aan de Musi-CI training worden op allerlei speelse manieren uitgedaagd weer intensief naar muziek te gaan luisteren en op een nieuwe manier met muziek om te gaan. Muziek-plezier, zelfwerkzaamheid en eigen regie staan voorop.

Tijdens de Musi-CI training wordt actief muziek gemaakt met behulp van bewezen methodes die het brein stimuleren, zoals neurologische muziektherapie (NMT) (Thaut \& Hoemberg, 2014) en de Ronnie Gardiner Methode (RGM) (Pohl, 2018). NMT richt zich o.a. op het trainen van aandacht met behulp van ritmische oefeningen. Aandacht speelt ook bij spraak-verstaan een belangrijke rol. RGM richt zich op het inschakelen van zoveel mogelijk gebieden in het brein door complexe klap-oefeningen. Door al deze activiteit in het brein 
ontstaan nieuwe verbindingen tussen hersengebieden, waar ook de auditieve verwerking van profiteert.

Het voelen van de maat geeft structuur aan de muziek waar je naar luistert; ritme kan in deze structuur worden ingebed. Het aanvoelen van de sfeer in een muziekstuk vertelt je welk gevoel die muziek bij je oproept, waarbij het (her)kennen van de klank van instrumenten meer kleur geeft aan de muziek. Uit onderzoek van Fritz en anderen (2009) blijkt dat de meeste mensen een vrolijke, treurige of angstaanjagende sfeer grotendeels hetzelfde beoordelen. Dit ondersteunt het bespreken van de ervaren sfeer met deelnemers. Door uitwisseling hierover leren deelnemers dat ze het vaak eens zijn over hoe de muziek op hen overkomt. Dit helpt om meer op hun eigen gevoel te gaan vertrouwen.

Het waarnemen van toonhoogteverschillen en melodisch contour blijkt de grootste uitdaging te zijn. Om training met veel herhaling mogelijk te maken, wordt gewerkt aan het ontwikkelen van een 'serious game'.

Met behulp van subsidie van ZonMw aan Stichting Musi-CI wordt gedurende 18 maanden gewerkt aan het ontwikkelen van een handboek voor de Musi- $C I$ training, in samenwerking met CI-teams van Radboudumc en UMC Utrecht en onderzoekers van de Hogeschool Arnhem-Nijmegen (HAN). In het ZonMW project 'Voor Elkaar' ligt de nadruk op inbreng van ervaringsdeskundigheid en participatie van de doelgroep bij het bereiken van het door hen gewenste resultaat. Deze participatie is onderdeel van de onderzoeksopzet, waarbij met vragenlijsten en evaluatieformulieren input en feedback van de deelnemers wordt verzameld. De inbreng van ervaringsdeskundigheid wordt gewaarborgd doordat Joke Veltman pianiste én CI-gebruiker - als projectleider en uitvoerder van de Musi-CI training werkt. Samenwerking met CI-dragers is belangrijk om zo dicht mogelijk bij de wensen en mogelijkheden van ons, de doelgroep, te blijven. Samenwerking met CI-teams is belangrijk om ervoor te zorgen dat de Musi-CI training aansluit bij de mogelijkheden binnen CI-revalidatie.

\section{Mogelijkheden voor zorgprofessionals}

Tijdens de reguliere gehoortraining binnen CI-revalidatie ligt de nadruk op het weer leren verstaan van spraak, met behulp van verhaaltjes, zinnen en tenslotte leren onderscheiden van op elkaar gelijkende woorden. Als toevoeging vanuit de Musi-CI training kan aanpassing aan het nieuwe geluid van het CI geprikkeld worden door veel verschillende geluiden waaronder muziek - aan te bieden. Zo kan er gewerkt worden met zingen en het luisteren naar verschillende toonhoogtes en timbres. 


\section{Muziek als brein-fitness}

Muziek is een complex geluid waarvoor veel verwerkingskracht van het brein nodig is, doordat gelijktijdig veel informatie wordt overgedragen, zoals maat, ritme, toonhoogte en timbre (Kraus \& Chandrasekaran, 2010). Het bestuderen van het brein bij muziek maken en muziek luisteren geeft inzicht in de complexe processen, die hierin een rol spelen. Dit zijn o.a. auditieve verwerking, aandacht, geheugen, motorische vaardigheden, emotionele respons, sociale communicatie, syntactische verwerking, betekenis geven, sociale cognitie en multimodale integratie als belangrijke psychologische processen (o.a. Koelsch, 2013). Ook Thaut en Hoemberg (2014) zien een duidelijke invloed van muziek op het brein. Goede breinfitness is het bespelen van een instrument. Alle actieve hersengebieden worden gekoppeld, omdat je gelijktijdig visueel, auditief en motorisch actief bent in een rijke, multi-sensorische bezigheid, zoals beschreven wordt door Lee en Noppeney (2011). In de Musi-CI training wordt naar actief musiceren gestreefd door het gebruik van NMT en RGM-technieken. De plasticiteit van het brein speelt een grote rol; ook het brein van ouderen beschikt over voldoende plasticiteit om te kunnen profiteren van (muziek)oefening (Schlaug, 2015). De focus ligt dus op training: met veel herhaling en aandacht luisteren naar muziek is muziek als brein-fitness.

Om de impact van de Musi- $C I$ training te verduidelijken, deel ik hieronder enkele quotes van deelnemers aan Ronde 1 en 2.

... Van het beluisteren naar de saxhoorns ben je, als je niet op gereed klikt, zo vier uur verder met het beluisteren van de muziek. 'ik heb er vandaag van genoten.' Ik vind het geweldig fijn om uitleg te krijgen over de saxhoorns en dan verder te gaan luisteren...

... Er is zich een groot proces bij me aan het voltrekken. Door de RGM (gisteren drie uur droog geoefend) en door het urenlang luisteren naar muziek worden er schijnbaar een aantal nieuwe wegen in mijn hersenen aangeboord. Regelmatig biggelen de tranen over mijn wangen als ik muziek beluister, terwijl ik vroeger alle muziek uit de weg ging...

... Wel kan ik zeggen dat ik luisteren het meest interessant vind, dat klappen houd $i k$ maar korte tijd vol, ritme voel ik goed aan en het pianospelen op de app is ook meer een tussendoortje wat me niet zo lang boeit. Proberen een liedje mee te spelen en de score opvoeren, maar ik kom niet verder dan 50 procent...

... Ik ben weer begonnen met piano spelen, nadat ik jaren om de piano heen gelopen ben. Nu ik meer aan het geluid van de piano gewend ben, heb ik er weer plezier in. Vooral het verder uit elkaar plaatsen van de handen helpt me om er weer chocola van te maken... 


\section{Conclusie}

Mijn persoonlijke ervaringen met CI-revalidatie en het weer terug veroveren van mijn vermogen van muziek te genieten liggen aan de basis van de Musi-CI training. Door de samenwerking met Radboudumc, UMC Utrecht, onderzoekers van de HAN én de subsidie van ZonMw kunnen de eerste stappen worden gezet. Kenmerkend voor de Musi-CI training is het werken aan meer muziek-plezier voor CI-gebruikers. Met de basiselementen van muziek als uitgangspunt wordt er gewerkt in kleine groepjes, maar vooral ook door de deelnemers zelf, thuis. Om deelnemers uit te dagen meer 'uren' te maken wordt gewerkt aan het ontwikkelen van een serious game, waarmee het volgen van melodie kan worden geoefend. Feedback op de eerste trainingen laat zien dat voor het overgrote deel van de deelnemers de deur naar muziek weer open gaat, een deur die voor de start van de Musi-CI training stevig dicht zat.

Het brein maakt met behulp van CI-revalidatie het weer kunnen verstaan van spraak mogelijk. Het geluid van muziek is complex omdat gelijktijdig veel informatie wordt overgedragen, namelijk maat, ritme, toonhoogte, timbre en harmonie/samenklanken. Hiervoor is veel verwerkingskracht in het brein nodig, zoals hierboven is besproken. Muziek kan derhalve dienen als brein-fitness. Extrapolerend vanuit de eerste positieve resultaten zie ik als perspectief dat de Musi- $C I$ training een zinvolle toevoeging kan zijn binnen CI-revalidatie.

Medio 2021 wordt het Handboek Musi-CI training gepresenteerd als eindresultaat van het ZonMw project. Hierna zijn vervolgstappen zoals effectmeting en validatie nodig. Andere onderzoeksvragen kunnen zijn:

- Welke bijdrage kan het verbeteren van de software van het CI leveren aan een betere klank van muziek met het CI

- Welke effecten heeft het CI op verwerking van geluid door het brein?

Film 'Luisteren met een kunst-oor': https://www.youtube.com/watch?v=W4mLya-F-9I De lange versie (15 minuten) in overleg met Joke Veltman en UMC Utrecht (info@jokeveltmanmuziek.nl).

Musi-CI training: www.musi-ci.nl

\section{Referenties}

Informatie over cochleair implantaat: https://www.opciweb.nl/ci/

Ronnie Gardiner Methode (RGM): https://rgm-nederland.nl/site/home

ZonMw, Voor Elkaar! https://www.zonmw.nl/nl/onderzoek-resultaten/gehandicapten-enchronisch-zieken/programmas/project-detail/voor-elkaar/musi-ci-muziek-voor-mensen-met-een-cochleair-implantaat/

Boyen, K., Langers, D. R., de Kleine, E., \& van Dijk, P. (2013). Gray matter in the brain: differences associated with tinnitus and hearing loss. Hearing research, 295, 67-78.

Eggermont, J. J. (2017). Acquired hearing loss and brain plasticity. Hearing Research, 343, 176-190. 
Fritz, T., Jentschke, S., Gosselin, N., Sammler, D., Peretz, I., Turner, R., ... \& Koelsch, S. (2009). Universal recognition of three basic emotions in music. Current biology, 19(7), 573-576.

Fuller, C. D. (2016). The effect of music on auditory perception in cochlear-implant users and normal-hearing listeners (Doctoral dissertation, Rijksuniversiteit Groningen).

Koelsch, S. (2012). Brain and music. John Wiley \& Sons.

Kraus, N., \& Chandrasekaran, B. (2010). Music training for the development of auditory skills. Nature reviews neuroscience, 11(8), 599-605.

Lee, H., \& Noppeney, U. (2011). Long-term music training tunes how the brain temporally binds signals from multiple senses. Proceedings of the National Academy of Sciences, 108(51), E1441-E1450.

Patel, A. D. (2014). Can nonlinguistic musical training change the way the brain processes speech? The expanded OPERA hypothesis. Hearing research, 308, 98-108.

Pohl, P. (2018). The Ronnie Gardiner method: An innovative music-based intervention for neurological rehabilitation-theoretical background and contemporary research with focus on Parkinson's disease. Neurophysiology and Rehabilitation, 1(1), 32-37.

Schlaug, G. (2015). Musicians and music making as a model for the study of brain plasticity. In Progress in brain research (Vol. 217, pp. 37-55). Elsevier.

Thaut, M., \& Hoemberg, V. (Eds.). (2014). Handbook of neurologic music therapy. Oxford University Press (UK). 